\section{Environmental influence on blood serum detection using ultraviolet 365}

\author{
Kelly P Kearse* \\ Knoxville Catholic High School, 9245 Fox Lonas Rd., Knoxville, TN, USA
}

\section{Summary}

The major use of alternative light sources (ALS) in the evaluation of bloodstains has been primarily focused on detection of whole blood, with relatively little attention to visualization of blood serum. Serum may become separated from blood pools during clotting, and because it is relatively invisible on certain backgrounds, go undetected by a perpetrator attempting to clean up a crime scene. Recently, Ultraviolet 365 (UV 365) was shown to be an effective tool in blood evaluation, useful for detection of even minute quantities of blood serum. Here the effects of environmental conditions on blood serum stain appearance were evaluated, including temperature, $\mathrm{pH}$, protease sensitivity, solubility, and aging. Interestingly, it was found that the UV fluorescence of serum increases upon exposure to heat, which was accompanied by color changes under visible light and decreased solubility in multiple solvents. The efficiency of visualization of serum stains was somewhat variable, depending on the type of material on which it was dried. Finally, the current study documents the effect of heating on formation of fluorescent serum halo rings in dried bloodstains. Taken together, these data demonstrate that blood serum detection may be affected by certain conditions that influence its visualization under both visible and UV light.

\section{More Information}

*Address for Correspondence: Kelly P. Kearse, Ph.D., Knoxville Catholic High School, 9245 Fox Lonas Rd., Knoxville, TN, USA, Tel: 865-560-0313;

Email: kelly.kearse@knoxvillecatholic.com

Submitted: March 12, 2021

Approved: March 25, 2021

Published: March 26, 2021

How to cite this article: Kearse KP Environmental influence on blood serum detection using ultraviolet 365. J Forensic Sci Res. 2021; 5: 030-036.

DOI: 10.29328/journal.jfsr.1001024

ORCiD: orcid.org/0000-0001-7713-171X

Copyright: @ 2021 Kearse KP. This is an open access article distributed under the Creative Commons Attribution License, which permits unrestricted use, distribution, and reproduction in any medium, provided the original work is properly cited.

Keywords: Boodstains; Serum; UV365, Bood serum stain

\section{(W) Check for updates}

OPEN ACCESS

\section{Introduction}

Compared to whole blood, relatively few methods exist for the detection of blood serum using ALS. In cases where the victim is moved, blood serum can be cast off during the clotting process, and because serum is relatively imperceptible on many materials under visible light, go unnoticed by a culprit trying to cover up a crime. Recent studies have shown that Ultraviolet 365 (UV 365) provides a simple, effective, and nondestructive ALS method in the detection of blood serum on a variety of surfaces [1].

Previous results on the effect of such variables as temperature and $\mathrm{pH}$ on blood appearance and evaluation are primarily restricted to those involving dried whole blood, liquid serum, or isolated serum proteins, such as albumin [2-6]. Indeed, relatively little information exists regarding the effect of environmental conditions on the characteristics of dried serum, and how such factors might affect its detection. To that end, a series of studies was performed to evaluate the appearance of blood serum stains under a variety of circumstances. These data show that serum properties can be affected by certain treatments, including those that influence serum appearance under both UV 365 and visible light. The implications of these findings in blood detection and analysis are discussed.

\section{Materials and methods}

\section{Whole blood and serum}

Human blood was obtained from healthy volunteers by the finger stick method using a Health Lancing device (CVS pharmacy ${ }^{\circledR}$, USA) fitted with a micro lancet (CVS pharmacy ${ }^{\circledR}$, USA). Blood was dropped onto Parafilm ${ }^{\circledR}$ M Laboratory Film (Bemis Company, Inc., Oshkosh, WI) and transferred to a $1.5 \mu \mathrm{l}$ Eppendorf ${ }^{\circledR}$ microcentrifuge tube (Eppendorf, Hamburg, Germany) using a 10-100 microliter $(\mu \mathrm{l})$ Eppendorf ${ }^{\circledR}$ micro pipettor (Hamburg, Germany), with the volume set at $100 \mu \mathrm{l}$; blood was then added to material as needed, using the same micro pipettor with the volume set at 5-10 $\mu$ l. Aged samples were stored in plastic trays with a lid for up to two years. For purification of blood serum, blood was allowed to clot for two hours in a $1.5 \mu$ l Eppendorf tube, then spun in a microcentrifuge (Qualitron Inc., Gyeonggi-Do, South Korea) for 1 minute. The supernatant was removed, and transferred to a new tube; this cycle was repeated $2 \mathrm{x}$ until no red material was visible. Additionally, human blood serum was obtained from Innovative Research (Innovative Research Company, Novi, MI), purchased as pooled human serum off the clot.

\section{Ultraviolet light sources}

Two UV light systems were used in these studies: a LED 
UV flashlight, $365 \mathrm{~nm}$, LED-UV301-356 nm (Shenzhen Lightfe Light Limited, Shenzhen, China), referred to as System 1; and two LED portable 3 watt UV light bulbs, $365 \mathrm{~nm}$, UV3W-365UV-E27-AC (Golden Gadgets, South El Monte, CA) positioned at a $\sim 45^{\circ}$ angle from the subject and fitted with a NUV M55.0 x 0.75 filter (Edmunds Optics, Barrington, NJ), referred to as System 2. All photographs were taken using a Sony RX100 digital camera, and a $425 \mathrm{~nm}$ long pass filter (Edmunds Optics, Barrington, NJ) was placed in front of the camera lens with System 2.

\section{Fabrics and materials}

Specific fabrics that were used in this study include: Whatman ${ }^{\circledR} 1 \mathrm{~mm}$ filter paper; commercial linens purchased from Joanne's fabric shop, designated types 1,3, 5-7; linen that was hand woven from natural, unprocessed flax, designated as type 2; natural unprocessed linen (chemical free, unbleached, undyed) made from $100 \%$ organically grown flax, designated as type 4; and a white cotton T shirt that had been worn and washed in commercial detergent for several years. All fabrics were obtained from the author's personal collection. Other materials include a stainless steel kitchen knife, wood flooring, ceramic tile, and a black leather wallet.

\section{Acid/base treatment and heating}

To ensure thorough soaking and uptake, filter paper was incubated in excess liquid for four hours in solutions having a pH of approximately 2-13 and allowed to thoroughly dry prior to addition of serum. The $\mathrm{pH}$ of solutions was verified by adding $10 \mu \mathrm{l}$ of solution to $100 \mu \mathrm{l}$ of universal indicator. For direct addition of acid or base to serum, approximately $45 \mu \mathrm{l}$ of serum was mixed with $5 \mu \mathrm{l}$ of $0.1 \mathrm{M} \mathrm{HCl}$ or $5 \mu \mathrm{l}$ of $0.01 \mathrm{M} \mathrm{NaOH} .10 \mu \mathrm{l}$ of the mixture was added to filter paper for evaluation of UVF and $10 \mu \mathrm{l}$ was mixed with $100 \mu \mathrm{l}$ of universal indicator solution to verify $\mathrm{pH}$. For heating, samples were heated in a Digital Dry Bath incubator with heating block (Four E's Scientific, Guangzhou, CN) for temperatures up to $100^{\circ} \mathrm{C}$, a countertop Comfee toaster oven (Midea Group, Midea, $\mathrm{CN}$ ) for temperatures up to $300^{\circ} \mathrm{C}$, or a free range oven (General Electric, Boston, MA) for temperatures up to $300{ }^{\circ} \mathrm{C}$.

\section{Solubility and protease treatment}

For solvent treatment, $10 \mu \mathrm{l}$ of blood or serum was added to filter paper and dried for at least one hour; samples were then cut in half and placed in a $1.5 \mu \mathrm{l}$ Eppendorf microcentrifuge tube containing $1.2 \mu \mathrm{l}$ of solvent for 3 hours with intermittent shaking. Samples were rinsed briefly with distilled water and allowed to dry before evaluation. The following solvents were used: distilled water, white vinegar (Kroger, Knoxville, TN), 5\% SDS (Sigma, St Louis, MO), 5\% Triton X-100 (CCS, LLC, Quakertown, PA), 5\% Tween 20 (Florida Laboratories Inc, Ft. Lauderdale, FA), DMSO (Heiltropfen, London, UK), 70\% isopropyl alcohol (Kroger, Knoxville, TN), 91\% isopropyl (CVS Pharmacy, Knoxville, TN), cholorform (Sigma, St. Louis, $\mathrm{MO}$ ), and Folex cleaning solution (Unified Grocers, Stockton, CA). For protease digestion, samples were dried onto filter paper and then resuspended in $1 \mu \mathrm{l}$ digestion buffer $(0.08$ M potassium phosphate, $4 \mathrm{mM} \mathrm{NaCl}, 3 \mathrm{mM} \mathrm{CaCl}, 0.5 \%$ SDS, $\mathrm{pH}$ 8.0) containing $10 \mu \mathrm{l}$ of proteinase K (recombinant, PCR grade) enzyme (Thermo Fisher Scientific, Waltham, MA). Samples were incubated for 1.5 hours at $37{ }^{\circ} \mathrm{C}$ and then transferred to a new tube containing fresh buffer and enzyme for a second incubation period.

\section{Results}

As shown in Figure 1, whole blood appeared relatively dark under UV, unlike blood serum, whose visualization was enhanced (Figure 1). Whole blood absorbs at this wavelength and does not fluoresce; the fluorescence of blood serum in whole blood is masked unless separation occurs [1].

The effect of $\mathrm{pH}$ on blood serum stain appearance was evaluated by adding serum to filter paper that had been previously soaked in solutions having a $\mathrm{pH}$ of approximately $2-12$, or by adding acid or base directly to serum and then transferring to filter paper. As demonstrated, no noticeable difference in serum UVF was observed using either method

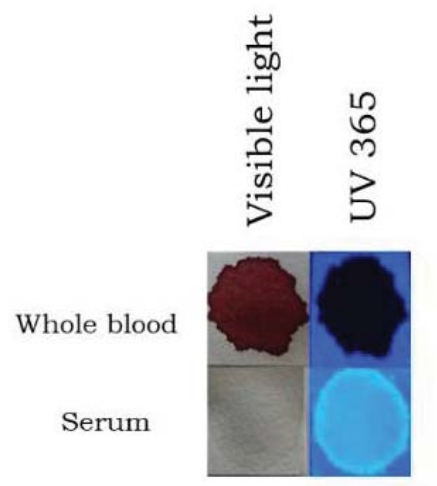

Figure 1: Bloodstain and serum stain appearance under visible light and UV. Whole blood and serum was added to filter paper and evaluated under visible (normal) light and UV 365 (system 1), (see Materials and Methods for details).

\section{A}

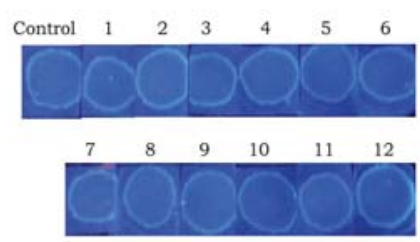

B

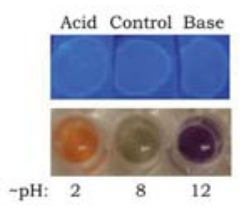

Figure 2: Effect of pH on serum appearance. (A). Serum was added to filter paper that had been soaked in solutions with the approximate $\mathrm{pH}$ as indicated. Samples were evaluated under UV 365 (system 1). (B). Top row: Acid, base, or distilled water (control) was mixed with serum and then transferred to filter paper. Samples were evaluated under UV 365 (system 1). Bottom row: An aliquot of each mixture was added to universal indicator to verify $\mathrm{pH}$ (see Materials and Methods for details). 
(Figure 2A,B). Next, the effect of temperature on serum stain appearance was examined by heating samples from $50{ }^{\circ} \mathrm{C}$ to $250{ }^{\circ} \mathrm{C}$ for ten minutes. As shown in Figure $3 \mathrm{~A}$, serum had a similar appearance in control, $50{ }^{\circ} \mathrm{C}$, and $100{ }^{\circ} \mathrm{C}$ groups, with a noticeable difference occurring at temperatures of $150{ }^{\circ} \mathrm{C}$ or higher (Figure 3A). At $150{ }^{\circ} \mathrm{C}$, serum had a light brownish/goldenrod appearance under visible light, which was associated with a brighter, yellowish UVF (Figure 3A). Increased temperature resulted in a reddish color under visible light and decreased UVF (Figure 3A). Although color changes in filter paper were apparent with heating (Figure 3A), comparable results for blood serum appearance were seen when glass slides were used (Figure 3B), demonstrating that heating effects can occur independently of cellulose and any small impurities that might be present in the filter paper. Relatedly, a heat-dependent increase in UVF of dried serum was seen with other materials (Figure 4), including wall tile, leather, wood flooring, a kitchen knife, wood flooring, and rock (Figure 4A,B), although the temperature threshold was variable. Examination of two types of carboard showed distinct differences. Serum added to corrugated cardboard showed enhanced UVF with heating (Figure 4B), unlike serum dried on a thinner type of carboard, which was not fluorescent at any temperature tested, although both samples had a similar appearance under both visible light and UV after heating at $250{ }^{\circ} \mathrm{C}$ (Figure 4B). Serum stains on a white cotton t-shirt were barely perceptible by UVF, even after heating (Figure 4B), although their appearance under visible light was similar to those on filter paper (Figure 3A) and other fabrics (see below). With white cotton textiles, the high background fluorescence is likely due to fluorescing whiteners which have

\section{A}

C $50^{\circ} 100^{\circ} 150^{\circ} 200^{\circ} 250^{\circ}$

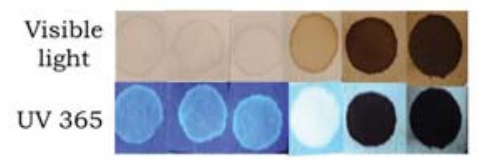

B

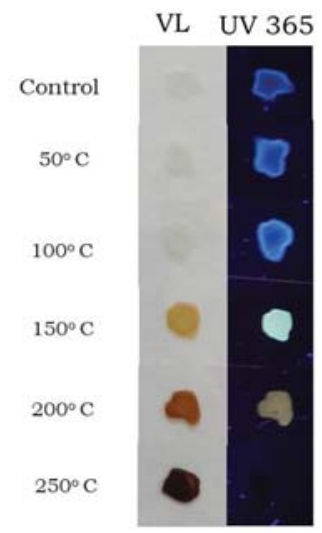

Figure 3: Effect of heat on serum appearance. Serum was added to filter paper (A) or glass slides (B) and after drying, heated for ten minutes at the indicated temperature. Samples were evaluated under visible (normal) light and UV 365 (system 1). In (A), C = Control; all temperatures are in ${ }^{\circ} \mathrm{C}$
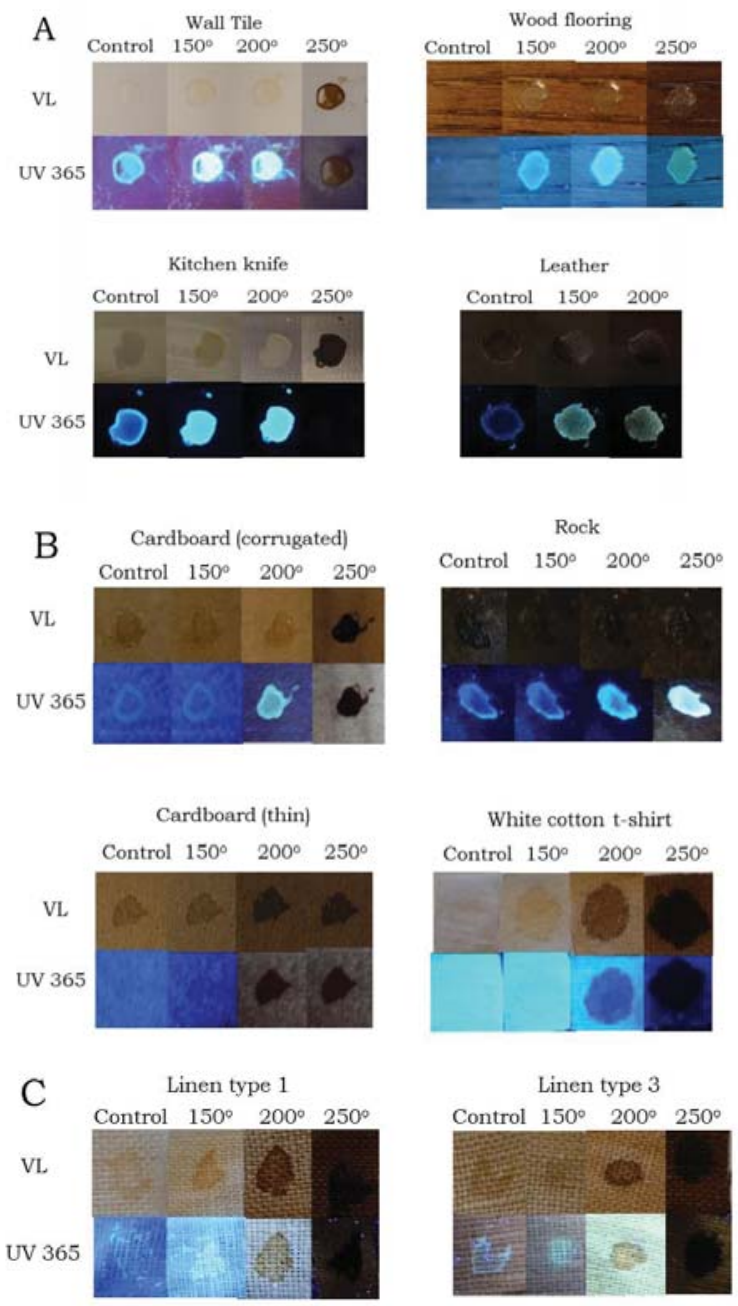

Linen type 3
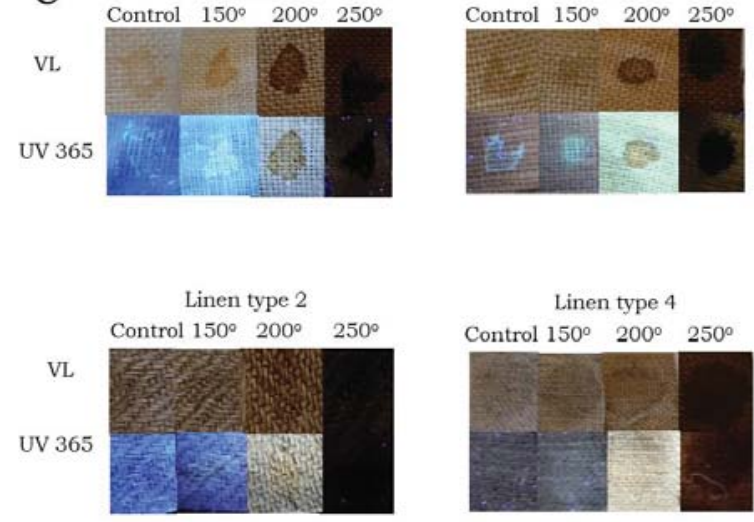

Figure 4: Effect of heat on the appearance of serum dried on various materials. Serum was added to various materials and after drying, heated for ten minutes at the indicated temperature (in ${ }^{\circ} \mathrm{C}$ ). For textiles, separate pieces were examined for each specific time point. For non-textiles, the same sample was heated sequentially with an increase in temperature. Samples were evaluated under visible (normal) light (VL) and UV 365 (system 2).

been added during its manufacture. When serum was added to several different types of linen and examined, the UVF results were variable in that serum was readily visible under uv on some linens before heating, but not others (Figure 4C). In general, UVF of serum was enhanced following heating, although the ease with which serum was visualized depended on the individual fabric (Figure 4C). In extension of these results, similar experiments were performed on an expanded group of textiles, applying both whole blood and blood serum before and after heating (Figure 5). Post-heating addition allowed for serum evaluation in the context of any changes in background (textile) appearance that might occur during the process. An experimental key is shown in Figure 5A. 
Pre-heating was required for increased UVF of serum, as serum added to filter paper post-heating showed a similar appearance as control groups (Figure 5A). Interestingly, a fluorescent halo was present at the periphery of heated blood (Figure 5A), which was evaluated in more detail (see below). Examination of an extended panel of textiles showed that similar to our previous results, visualization of serum by UVF on untreated and heated linens was variable, ranging from barely visible to clearly detected (Figure 5B,C). With certain material (linen types 1,2,6,7), extended heating resulted in decreased UVF, whereas in others (filter paper, linen types 3 and 5), detectability was maintained (Figure 5A-C). In all cases, no increase in serum UVF was apparent when added post-heating, emphasizing that a temperature effect on serum is the major factor in the result. When the effect of heating

\section{A}
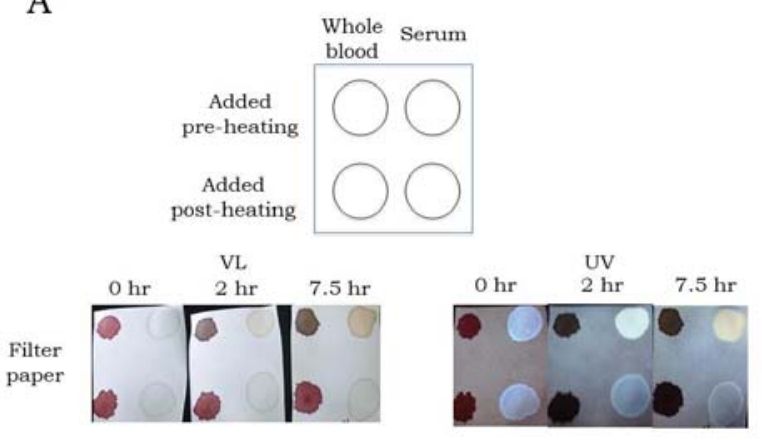

B
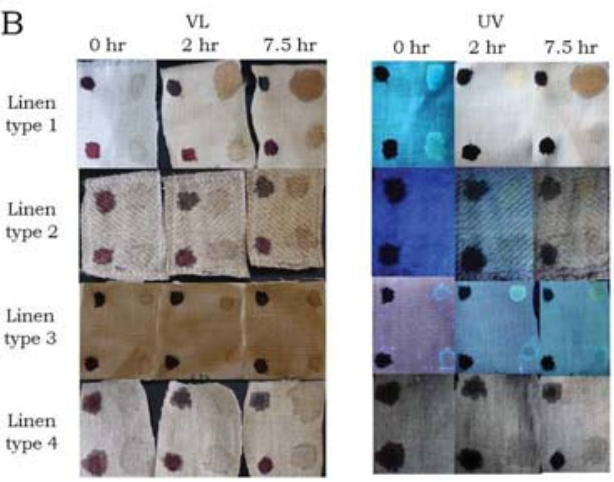

C

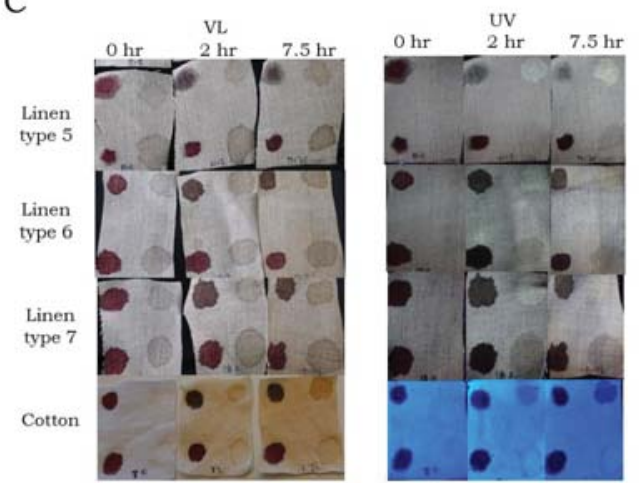

Figure 5: Effect of heat on the appearance of whole blood and serum dried on various textiles. Serum was added to various textiles and after drying, sequentially heated for the indicated time period at $150{ }^{\circ} \mathrm{C}$ (see key, panel A for reference). After heating, whole blood and serum were applied again (see key, panel A for reference). Samples were evaluated under visible (normal) light (VL) and UV 365 (system 2). on bloodstains was examined in more detail, it was noted that a fluorescent serum halo ring was apparent after only ten minutes of heating at $150{ }^{\circ} \mathrm{C}$ (Figure 6A, arrow), and less noticeable with higher heating (Figure 6A), perhaps because the serum has begun to color shift to a darker appearance (Figure 3A,B).

Serum halo rings were also induced by heating bloodstains dried on other materials, such as glass and leather (Figure 6B). Interestingly, when aged bloodstains ( $\sim 2$ years old) were heated no serum halo rings were apparent (Figure 6C).

A

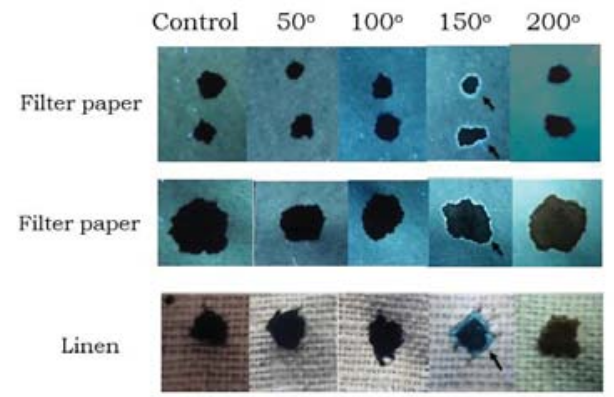

B

Whole blood: Whole blood:
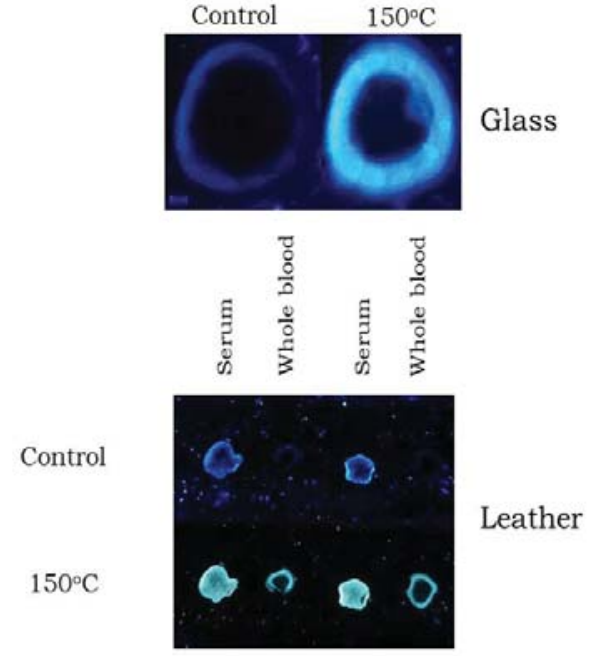

$\mathrm{C}$

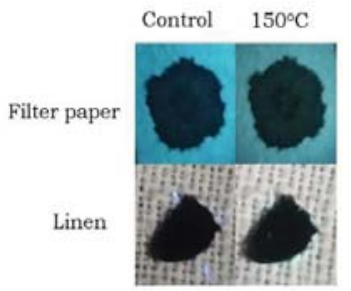

Figure 6: Heat-induced fluorescent halo rings in whole blood. (A) Whole blood was added to filter paper or linen (type 3), and after drying, heated for ten minutes at the indicated temperature (in ${ }^{\circ} \mathrm{C}$ ). Samples were evaluated under UV 365 (system 2). A different sample was used for each time point. (B) Top: Whole blood was added to glass microscope slides and after drying, photographed, then heated for ten minutes at $150 \mathrm{oC}$ and photographed again. Bottom: Serum and whole blood was added to leather and after drying, photographed, then heated for ten minutes at $150 \mathrm{oC}$ and photographed again. Samples were evaluated under UV 365 (system 2). (C) Whole blood that had been added to filter paper or linen (type 3) and aged for two years was photographed, then heated for ten minutes at $150^{\circ} \mathrm{C}$ and photographed again. Samples were evaluated under UV 365 (system 2). 
Taken together, these results show that heating resulted in increased UVF of dried serum on many materials, although the degree of visualization was dependent upon the background fluorescence of the substance on which the serum had dried. Additionally, these data document that heating of dried bloodstains was associated with the appearance of fluorescent halo rings at the periphery, which was not observed for aged blood (see discussion).

The solubility of whole blood and blood serum in multiple solvents was examined, showing similar solubility profiles for both (Figure 7A,B). Solvents that were ineffective were isopropyl alcohol, DMSO, and chloroform (Figure 7A,B). In contrast, bloodstains and serum stains were readily dissolved in water, glycerol, vinegar, Triton-X 100, SDS, Tween, and spot-
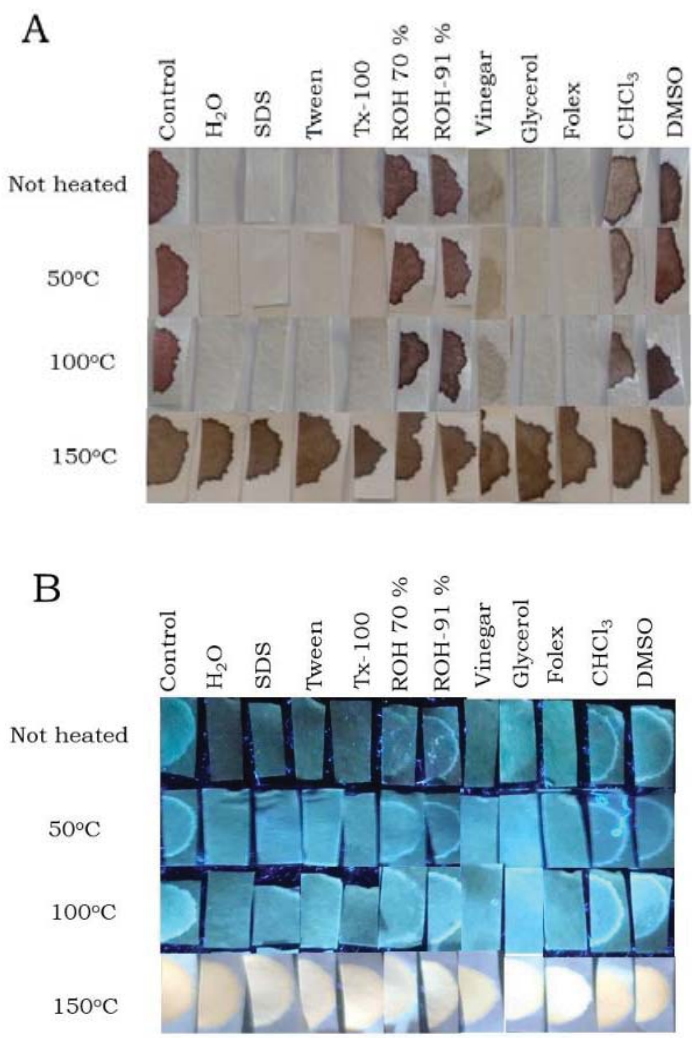

$\mathrm{C}$

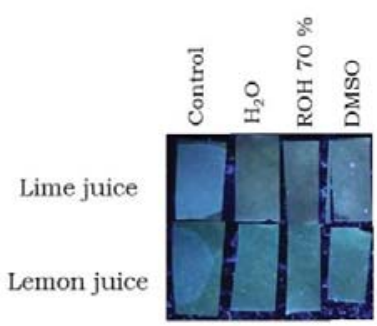

Figure 7: Influence of heating on the solubility of whole blood and blood serum. Whole blood $(A)$ or serum $(B)$ were added to filter paper and after drying, heated for ten minutes at the indicated temperature. Samples were then soaked in various solvents for approximately three hours at room temperature. $\mathrm{ROH}=$ alcohol. After drying, bloodstains (A) were evaluated under visible (normal) light, and serum stains (B) under UV 365 (system 2). (C) Lime juice and lemon juice were added to filter paper and after drying, soaked in various solvents for approximately three hours. After drying, samples were evaluated under UV 365 (system 2). removal solution (Folex), (Figure 7A,B). Following heating at $150{ }^{\circ} \mathrm{C}$ for ten minutes, neither blood nor serum were soluble in any of the solvents tested (Figure 7A,B). Previous studies demonstrated that certain fruit juices showed similar UVF as human serum and that serum halo rings from clotted blood could be mimicked by their addition to whole blood [1]. In the current report, juices from both lime and lemon were found to be soluble in both isopropyl alcohol and DMSO (Figure 7C), providing an effective means for distinguishing them from serum (Figure 7B). To further define the temperature range at which bloodstains and serum stains became water insoluble, experiments were performed within the restricted range of $100{ }^{\circ} \mathrm{C}$ to $150{ }^{\circ} \mathrm{C}$. As shown in Figure 8, a partial decrease in water solubility was observed at $130{ }^{\circ} \mathrm{C}$, which was fully complete at $150^{\circ} \mathrm{C}$ (Figure 8 ). Aged serum ( $~ 2$ years) showed an increased UVF relative to freshly dried serum, and unlike freshly dried serum, was not readily soluble in water (Figure 9). Similarly, serum stains that were briefly ironed showed increased UVF relative to control serum, and were water insoluble (Figure 9). Water insolubility was also observed for both aged bloodstains and ironed blood (Figure 9). Together, these results show that dried blood and serum are dissolved by a similar profile of solvents and that their solubility is markedly decreased upon heating. Additionally, these data show that aged serum shows increased UVF relatively to that which is freshly dried, and like heated serum, was water insoluble. It was also noted that certain solutions showing similar UVF as serum (fruit juices), may be distinguished from serum by use of solvents such as DMSO or isopropyl alcohol.

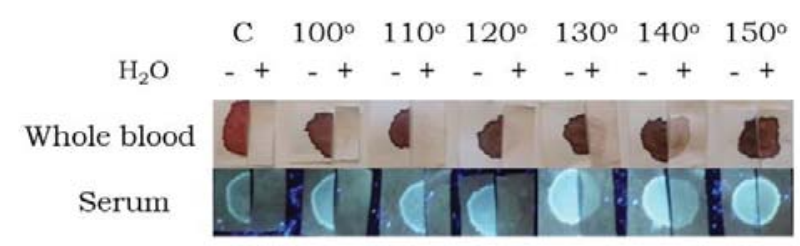

Figure 8: Influence of heating on water solubility of bloodstains and serum stains. Whole blood and serum were added to filter paper and after drying, heated for ten minutes at the indicated temperature (in ${ }^{\circ} \mathrm{C}$ ). $\mathrm{C}=$ Control. Samples were cut in half; one-half was untreated, the other was soaked in water for approximately three hours at room temperature. After drying, samples were evaluated under visible (normal) for bloodstains and UV 365 (system 2) for serum stains.

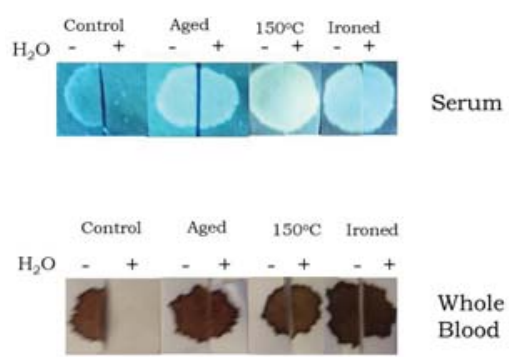

Figure 9: Water solubility of various types of bloodstains and serum stains. Fresh whole blood or serum were added to filter paper and after drying, either not treated (control), heated for ten minutes at $150{ }^{\circ} \mathrm{C}$, or ironed for three minutes at the highest temperature setting (linen). Whole blood or serum that had been added to filter paper, dried, and aged for approximately two years was also included. Samples were cut in half, one-half was untreated, and the other was soaked for three hours in water at room temperature. After drying, samples were evaluated under UV 365 (system 2) for serum stains and visible (normal) light for bloodstains. 
Finally, the susceptibility of both serum stains and bloodstains to protease digestion was examined. As demonstrated, freshly dried serum and whole blood were readily dissolved in buffer alone (Figure 10), unlike aged samples which required the presence of enzyme for removal (Figure 10). Neither heated serum stains nor heated bloodstains were efficiently digested by protease (Figure 10), and both were fully resistant at higher temperatures $\left(200{ }^{\circ} \mathrm{C}\right)$, (Figure 10). Ironed serum was not completely removed by protease digestion (Figure 10), even after multiple rounds of enzyme addition (see Materials and Methods). Bloodstains that had been ironed were for the most part digested away, although some residual serum appeared to persist (Figure 10), which was verified by UV examination (data not shown). Taken together, these results show that aged bloodstains and aged serum stains remained susceptible to enzymatic digestion by protease, unlike heated samples, which were relatively resistant.
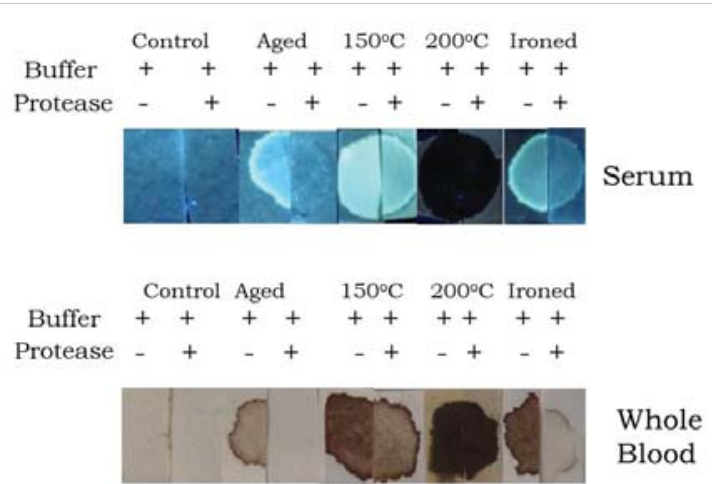

Figure 10: Protease digestion of various types of bloodstains and serum stains. Fresh whole blood or serum were added to filter paper and after drying, either not treated (control), heated for ten minutes at $150{ }^{\circ} \mathrm{C}$, or ironed for three minutes at the highest temperature setting (linen). Whole blood or serum that had been added to filter paper, dried, and aged for approximately two years was also included. Samples were cut in half, and incubated in digestion buffer in the presence or absence of protease (see Materials and Methods for details). After drying, samples were evaluated under UV 365 (system 2) for serum stains and visible (normal) light for bloodstains.

\section{Discussion}

The current study has evaluated the influence of various environmental conditions on the appearance of blood serum stains and their detection using UV 365. These results show that UVF detection of serum is enhanced upon exposure to temperatures of approximately $150{ }^{\circ} \mathrm{C}$, and decreased with higher temperatures $\left(200{ }^{\circ} \mathrm{C}-250{ }^{\circ} \mathrm{C}\right)$, accompanied by a reddish color in visible light. While heating resulted in enhanced UVF of serum on the vast majority of substances tested, the effect was somewhat variable with certain textiles, depending upon the particular material on which the serum was dried. For some, such as thin cardboard, white cotton, and certain types of linen, UV detection of serum was very difficult on control samples, and only marginally improved after serum stains were heated, underscoring the influence of the fluorescent background of the material on which the serum has dried. This analysis may be useful in crime scenes containing both fresh and aged blood, although the material on which the blood or serum has dried may influence the efficiency of detection. In the presence of fresh blood, the usefulness in analyzing serum with this method is that due to its relative invisibility on many substrates in visible light, serum may go unnoticed by a perpetrator focusing their cleanup efforts on removal of red stains from the area; as previously noted, serum may become separated from whole blood during the clotting process, particularly in the case where a victim may have been moved [1]. Serum fluorescence increases with aging, enhancing the possibility of its detection over time. As demonstrated in this report, this method is relatively sensitive and capable of detecting even minute quantities of serum, as small as 5-10 $\mu \mathrm{l}$ of original volume.

Previous studies have shown that liquid whole blood begins to separate into its components at relatively mild temperatures; Larkin and Banks reported that when impinging blood reaches a metal surface at $\sim 50{ }^{\circ} \mathrm{C}+$ serum separation begins to occur [5]. The current report represents the first evaluation of a heating effect on serum present in dried bloodstains, and especially the use of ALS, UV 365, for its detection. These results suggest that separation occurs between blood cells and serum in dried bloodstains with heating; it is also possible that a thin edge of serum may be present around the perimeter of bloodstains at room temperature, whose presence is disclosed upon heating. Thin florescent border rings were not observed in bloodstains heated at higher temperatures, consistent with diminished UVF observed for serum stains, although it also possible that some serum evaporation may occur [5]. It was also noted in these studies that fluorescent border rings were not observed in aged bloodstains, approximately two years old. It has been found that two-month old bloodstains show a similar result as that of days old blood, i.e. a fluorescent border is evident after heating (unpublished observations), indicating that changes in dried bloodstains progress beyond this time period. Future efforts will be directed toward further defining the specific stages of serum separation that occur in bloodstains under various conditions over time.

Aged serum showed increased UVF relatively to that which had been recently dried, which was associated with a decrease in water solubility. It is notable that unlike analysis of whole blood, serum detection may be enhanced with the passage of time, depending upon the environmental conditions that might be present. Verification that serum was in fact present would require confirmatory testing, analogous to detection of semen or saliva with ALS methods. Presumably, denaturation of dried serum by either medium heat treatment or aging results in an aggregated state that exhibits increased UVF, although the precise molecular basis for this observation remains to be determined.

Similar to whole blood, it was found that certain solvents were ineffective at solubilizing dried blood serum, including 
$70 \%$ isopropyl alcohol, a solvent that readily cleans fresh blood off of many relatively nonabsorbent surfaces. Although water appeared to efficiently disrupt the intermolecular forces between dried serum and cellulose, this effect began to curtail with short exposure to medium temperatures or aging at room temperature (for approximately two years). Experiments are currently underway to further define the time period at which dried serum shifts to water insolubility and enhanced UVF during aging. Both aged serum and aged whole blood remained susceptible to protease removal, whereas heated samples did not, suggesting that specific stages of blood denaturation might exist that could be further defined by more detailed examination into the molecular basis of whole blood and blood serum aggregation.

\section{Acknowledgment}

Thank you to Samuel Pellicori for interesting discussion (Pellicori Optical Consulting, Santa Barbara, CA).

\section{References}

1. Kearse KP. Ultraviolet 365 as an Alternative Light Source for Detection of Blood Serum. J Forensic Sci. 2020; 65: 1716-1721. PubMed: https://pubmed.ncbi.nlm.nih.gov/32343369/

2. Saito $M$, Taira $H$. Heat Denaturation and Emulsifying Properties of Plasma Protein. Agric Biol Chem. 1987; 51: 2787-2792.

3. Brady T, Tigmo J, Graham G. Extreme Temperature Effects on Bloodstain Pattern Analysis. I.A.B.P.A Newsletter. 2002; 3-20.

4. Borzova VA, Markossian KA, Chebotareva NA, Kleymenov SY, Poliansky NB, et al. Kinetics of Thermal Degradation and Aggregation of Bovine Serum Albumin. PloS One. 2106; 11: e0153495.

PubMed: https://pubmed.ncbi.nlm.nih.gov/27101281/

5. Larkin BAJ, Banks CE. Preliminary Study on the Effect of Heated Surfaces Upon Bloodstain Pattern Analysis. J Forensic Sci. 2013; 58: 1289-1296.

PubMed: https://pubmed.ncbi.nlm.nih.gov/23865610/

6. Tontarski KL, Hoskins KA, Watkins TG, Brun-Conti L, Michaud AL. Chemical Enhancement Techniques of Bloodstain Patterns and DNA Recovery after Fire Exposure. J. Forensic Sci. 2009; 54: 37-48. PubMed: https://pubmed.ncbi.nlm.nih.gov/19018938/ 